\title{
Nível de Evidenciação Contábil de Organizações do Terceiro
}

\section{Disclosure Level of Nonprofit Organizations}

\author{
Marcus Vinicius Moreira Zittei \\ Doutorando em Ciências Contábeis e Administração pela Universidade Regional de Blumenau, Brasil \\ marcuszittei@gmail.com \\ http://lattes.cnpq.br/7947828317635699 \\ Leandro Politelo \\ Mestre em Ciências Contábeis pela Universidade Regional de Blumenau, Brasil \\ politelo@unochapeco.edu.br \\ http://lattes.cnpq.br/5624964872181542 \\ Jorge Eduardo Scarpin \\ Doutor em Controladoria e Contabilidade pela Universidade de São Paulo, Brasil \\ jscarpin@gmail.com \\ http://lattes.cnpq.br/6474056681420203
}

Resumo: Esta pesquisa objetiva identificar o nível de evidenciação contábil das entidades do terceiro setor participantes do projeto de Desenvolvimento de Princípios de Transparência e Prestação de Contas em Organizações da Sociedade Civil - BID. A população da pesquisa é composta por 76 entidades, e a amostra compreendeu 15 entidades que divulgaram sua prestação de contas em seus sítios. Para coleta dos dados foi elaborado um check list composto por 63 itens, destes, 53 baseados no Pronunciamento Técnico CPC 26 e 10 itens baseados na norma NBC T 10.19. Os resultados da pesquisa mostram que as entidades enfatizam a evidenciação das informações qualitativas e apresentam informações quantitativas de maneira sintética em sua maioria. Conclui-se que o nível médio de evidenciação das entidades participantes do projeto foi de $27 \%$, percebendo assim necessidade de estudos para apresentar as reais necessidades de evidenciação e fomentar normas específicas para o setor.

Palavras-chave: Terceiro Setor, Evidenciação contábil, Accountability.

Abstract: The purpose of this study is to identify the disclosure level of nonprofit organizations that participate in the project of the Development of Principles of Transparency and Provision of Accounts in Civil Society Organizations - BID. The researched population is composed by 76 entities and the sample included 15 entities that disclosed their provision of accounts in their sites. In order to collect data, a check list of 63 items was created, out of which 53 were based in IAS 26 and 10 items were based on NBC T 10:19 standard. The survey results show that the nonprofit organizations emphasize the disclosure of qualitative information, and present mostly quantitative information in a synthetic manner. It is possible to conclude that the average level of disclosure of the organizations participating in the project was $27 \%$. Thus, studies are necessary, in order to present the real needs of disclosure and encouragement of specific standards for the sector.

Key-words: Nonprofit organizations, Disclosure, Accountability.

Texto completo em português: http://www.apgs.ufv.br Full text in Portuguese: http://www.apgs.ufv.br

\section{INTRODUÇÃO}

O terceiro setor surgiu para cobrir uma lacuna existente entre o setor público e o privado. Conforme Campos, Moreira e Scalzer (2014), sua existência é percebida já na civilização egípcia, mas aparece de forma mais consolidada na Grécia; na época, com um cunho mais cultural e artístico (Campos et al., 2014). Entretanto, no contexto atual, sua finalidade está em cobrir os serviços que o estado deveria oferecer e por algum motivo não o faz; desta forma, apesar de ter constituição privada, tem caráter público e finalidade social (Olak \& Nascimento, 2010), fatores que contribuem para que esse setor venha-se consolidando ao longo do tempo (Carneiro, Oliveira \& Torres, 2011).

O aumento de desigualdades sociais, conflitos étnicos, catástrofes ambientais, bem como a privatização de serviços essenciais e a desregulamentação de políticas sociais, são fatores que contribuíram e ainda contribuem para o surgimento e consolidação do terceiro setor na tentativa de minimizar e até mesmo solucionar os problemas sociais. Esses novos atores sociais atuam em movimentos sociais e agem em prol do bem público (Almeida, 2007), tanto em relação à satisfação de necessidades pessoais básicas quanto em áreas culturais e artísticas (Campos et al., 2014)

A busca do terceiro setor por alternativas para amenizar os problemas gerados pela ineficiência do Estado em atender às demandas sociais proporcionou o grande crescimento desse setor e, em consequência, sua relevância econômica. (Carneiro et al., 2011). O contínuo aumento dessas entidades tem gerado também uma competitividade entre elas pela captação de recursos públicos e privados (Carneiro et al., 2011).

Nessa realidade, faz-se necessário que as organizações sem fins lucrativos sejam transparentes em seus processos e prestem conta de suas atividades e projetos desenvolvidos (Costa, Ramus \& Andreaus, 2011; Campos et al., 2014); porém, pesquisas indicam que as entidades desse setor não se mostram preocupadas no aspecto das divulgações contábeis financeiras e não financeiras ou mesmo de suas atividades e gestão de recursos (Cruz, 2010; Carneiro et al., 2011). 
Atan, Zainon e Wah (2012) e Gandía (2011) concluíram em sua pesquisa que as doações recebidas pelas organizações sem fins lucrativos são influenciadas pelo nível de divulgação destas; porém, a maioria das entidades de sua amostra não possuía como prática a divulgação de suas demonstrações contábeis e a prestação de contas à comunidade.

Complementa essa questão o fato de que as entidades do terceiro setor assumem um papel social do Estado e responsabilidades perante a sociedade (Costa et al., 2011). Por esse motivo, devem prestar contas de suas atividades e seus projetos a partir de sua missão e seus objetivos. Ademais, essa prática contribui para que sua legitimidade e importância sejam fundamentadas na sociedade (Costa et al., 2011).

Nesse contexto, apresenta-se a questão problema deste estudo: qual o nível de evidenciação contábil das entidades do terceiro setor participantes do projeto de Desenvolvimento de Princípios de Transparência e Prestação de Contas em Organizações da Sociedade Civil - BID? Assim, o objetivo desta pesquisa é identificar o nível de evidenciação contábil das entidades do terceiro setor participantes do projeto de Desenvolvimento de Princípios de Transparência e Prestação de Contas em Organizações da Sociedade Civil - BID.

O estudo se justifica nas palavras de Almeida (2007): a accountability tem sido pouco explorada nos estudos sobre 0 terceiro setor e organizações sem fins lucrativos, e essa prática (accountability) está intimamente relacionada à legitimidade dessas entidades. Ainda, conforme Campos et al. (2014), a expressividade das organizações do terceiro setor no Brasil e no mundo gera uma demanda crescente de estudos que possibilitem um maior e melhor conhecimento da realidade dessas entidades nas diversas ciências, de forma mais expressiva em contabilidade e em economia.

A relevância deste estudo é percebida também nas pesquisas de Cruz (2010), Gandía (2011), Atan et al. (2012), na qual investigaram a prática de divulgação de informações contábeis ao público externo e identificaram que, em sua maioria, as entidades não divulgavam publicamente suas informações, indicando um baixo nível de transparências das empresas do terceiro setor.

Essa questão é complementada pela crescente demanda do terceiro setor junto à sociedade que, segundo Cruz, Quandt, Martins e Silva (2010), depende de recursos financeiros para ser suprida e, conforme pesquisas como as de Weisbrod e Dominguez (1986), Keating e Frumkin (2003), Trussel e Pearsons (2007), Brito, Oliveira, Santos, Luca, e Oliveira (2008), Cruz (2010), Atan et al. (2012), a doações recebidas por essas entidades está relacionada positivamente com o nível de divulgação de informações dessas organizações.

\section{FUNDAMENTAÇÃO TEÓRICA}

Para compreensão adequada do terceiro setor, é preciso o esclarecimento de que existem três setores de atividades dentro da sociedade: o Estado (primeiro setor); entidades privadas ou de mercado (segundo setor) e o das atividades sem fins lucrativos, que se enquadram no terceiro setor (Cunha \& Matias-Pereira, 2012; Campos et al., 2014).

O primeiro setor, que é o Estado, tem a finalidade de promover o atendimento das demandas públicas como saúde, educação e segurança, e suas atividades são mantidas por meio arrecadação de tributos (Ebsen \& Laffin, 2004). Já no segundo setor, que são as entidades privadas ou de mercado, suas atividades envolvem troca de bens ou serviços para obtenção de lucro sobre o capital investido (Coelho, 2000).

Quanto ao terceiro setor, pode-se dizer que é um projeto social. Ele surge na voluntariedade da própria sociedade e não visa a lucro. Conforme Coelho (2000, p. 40), é o setor "em que as atividades não seriam nem coercitivas nem voltadas para o lucro [...], suas atividades visam 0 atendimento das necessidades coletivas e muitas vezes públicas", e possui como um de seus principais objetivos encontrar soluções para as desigualdades sociais no país (Campo et al., 2014).

No Brasil, dentro do terceiro setor, há vários conjuntos compostos de organizações sem fins lucrativos, mas todos envolvem o trabalho voluntário; o setor sustenta as práticas de caridade, da filantropia e do mecenato (Araújo, 2005). Essa presença considerável do terceiro setor indica uma limitação e ineficiência do Estado brasileiro (Olak \& Nascimento, 2010; Carneiro et al., 2011; Cunha \& Matias-Pereira, 2012). A consolidação das entidades sem fins lucrativos é, inclusive, percebida na Lei 13.019/2014, que regulamenta questões do terceiro setor e também estabelece regime de cooperação para consecução de finalidades de interesse público.

À medida que o terceiro setor surge com a finalidade de suportar a ineficiência do Estado e não possui foco lucrativo, mas tão somente o fim social, sua continuidade depende dos recursos advindos de doações recebidas de organizações privadas e da própria sociedade (Cunha \& Matias-Pereira, 2012; Piza, Parisi, Megliorini \& Gallo, 2012). A partir do momento em que entidades beneficentes recebem recursos por meio de doações pela sociedade e têm como contrapartida a necessidade da gestão adequada desses recursos recebidos, surge a accountability (Piza et al., 2012). Accountability se refere ao cumprimento, à responsabilidade e transparência das entidades ao prestarem contas aos mais diversos usuários (Almeida \& Ferreira, 2007).

Falconer (1999) afirma que a accountability, apesar de poder significar pouco mais do que a publicação de um relatório anual com dados de projetos e informações contábeis, também representa uma postura de responsabilidade da gestão exercitada em seu cotidiano frente a públicos internos e externos. Para Assis, Mello e Slomski (2006) a accountability surge, portanto, da necessidade da prestação de contas por parte dos gestores das entidades do terceiro setor, dos resultados obtidos decorrentes dos recursos utilizados que foram recebidos em forma de doações. Dessa forma, a accountability será abordada nesta pesquisa no escopo da necessidade de prestação de contas pelos gestores de entidades do terceiro setor, não abrangendo as demais conotações trazidas a partir do termo. 
$\mathrm{Na}$ visão de Oliveira (2009), para as entidades do terceiro setor existem dois tipos de prestação de contas: a financeira e a não financeira. A prestação de contas financeira refere-se ao destino, à forma, à distribuição e ao uso dos recursos financeiros, e a prestação de contas não financeira é focada nos resultados obtidos a partir da aplicação dos recursos, em outras palavras, nos resultados obtidos em relação à finalidade e missão da organização. Carneiro et al. (2011) complementam argumentando que, nesses relatórios (não financeiros), as organizações descrevem o que se realizou e como se realizaram as atividades por elas propostas.

O amplo universo de organizações que compõem o terceiro setor necessita, devido ao seu caráter público, atuar de forma transparente e prestar contas das atividades por elas desenvolvidas bem como a forma como os seus recursos estão sendo utilizados (Almeida \& Ferreira, 2007; Costa et al., 2011; Piza et al., 2012; Campos et al., 2014),

A relação entre a importância das entidades prestarem conta de suas atividades e as doações de recursos financeiros e não financeiros recebidas por elas é destacada por Soldi, Hatz, Santos, e Silva (2007), que salientam que essa relação com diferentes grupos de interesse nas esferas pública e privada torna a transparência na prestação de contas a todos os seus financiadores uma questão inerente à própria natureza dessas organizações, entendimento compartilhado também por Cunha e Matias-Pereira (2012).

Piza et al. (2012) estendem a obrigação que as entidades do terceiro possuem em divulgar informações de suas atividades ao entenderem que o governo também é usuário das demonstrações contábeis dessas organizações devido à desoneração que o governo concede às entidades por meio de imunidade e isenções fiscais e seu papel fiscalizador em garantir que estas mantêm o efetivo caráter sem fim lucrativo.

Nesse sentido, a transparência de todas as ações desenvolvidas pelas entidades do terceiro setor seria uma de suas principais características (Campos et al., 2014). Elas estariam obrigadas a prestar contas de suas ações desenvolvidas, serviços oferecidos, seu desempenho e a forma como seus recursos são utilizados (Almeida \& Ferreira, 2007; Zainon, Atan, Wah, \& Ahmad, 2012, Campos et al., 2014).

Atenua-se a questão da importância das entidades sem fins lucrativos serem transparentes, o fato de a Lei 13.019/2014 estabelecer questões vinculadas à divulgação de informações dessas entidades por meio de prestação de contas bem como seguir diferentes premissas quanto ao uso e à aplicação de seus recursos. $O$ interesse legal em estabelecer requisitos de prestação de contas revela a necessidade percebida de maior transparência pelo terceiro setor.

Falconer (1999) conclui que as organizações sem fins lucrativos atingirão o sucesso e simultaneamente maximizarão o benefício social de sua atuação ao prestarem contas a alguém. Conforme Assis et al. (2006) essas entidades, que são importantes para a população, passam por dificuldades geradas pela desconfiança com que a sociedade as enxerga. "Isso ocorre, sobretudo, devido à falta de transparência dos recursos arrecadados e dos resultados alcançados por estas instituições." (Assis et al., 2006, p. 1)

Pode-se dizer, então, que a transparência é um fator determinante na sobrevivência do terceiro setor, e, por esse motivo, é necessário que essas entidades prestem contas dos seus atos aos investidores sociais, doadores e patrocinadores (Assis et al., 2006; Brito et al., 2008). A transparência, portanto, mostra-se como uma questão inerente às entidades de terceiro setor (Assis et al., 2006).

Almeida e Ferreira (2007) destacam que ao se estabelecer parcerias entre as entidades e empresas financiadoras, quer sejam privadas ou públicas, as exigências por elas estabelecidas devem ser consideradas. Porém, existem os que não exigem prestação de contas, mas esta acaba por lhes ser devida por se tratar de serviço de caráter público e por estarem na base da organização como doadores, voluntários, beneficiários, a comunidade auxiliada e até mesmo a sociedade em geral (Carneiro et al., 2011).

Apesar do destaque dado pela literatura ao fato de que a divulgação de informações e a prestação de contas deve ser uma realidade nas entidades do terceiro setor devido a sua dependência da sociedade no que diz respeito ao seu financiamento e também à sua finalidade social (Almeida \& Ferreira, 2007; Brito et al., 2008; Carneiro et al., 2011; Gandía, 2011; Cunha \& Matias-Pereira, 2012; Zainon et al., 2012; Campos et al., 2014), as entidades, por vezes, não se mostram transparente quanto à arrecadação e utilização de recursos, e isso acaba por repercutir negativamente à imagem dessas entidades.

Assis et al. (2006) apresentam essa problemática ao afirmar que muitas campanhas de arrecadação são veiculadas na televisão e em outros meios de comunicação, mas poucas são as que apresentam valores arrecadados ou aplicados e muito menos as que demonstram os resultados que as entidades produziram com os recursos que receberam.

Esse problema também é exposto por Falconer (1999, p. 7), no que diz respeito à falta de transparência: "Ouve-se, simultaneamente ao discurso que idealiza o setor, que estas entidades são mal geridas, excessivamente dependentes, amadoras e assistencialistas em sua atuação, e, por vezes, sujeitas a motivações pouco filantrópicas, para não dizer criminosas".

Evidências empíricas demonstram que a prestação de contas e a divulgação de informações contribuem para que a sociedade financie as entidades do terceiro setor (Cunha \& Matias-Pereira, 2012). O trabalho seminal de Weisbrod e Dominguez (1986) apresentou como resultado que a disponibilidade de informações como o preço e a qualidade dos produtos da organização influenciam positivamente nas doações individuais para as entidades do terceiro setor.

Keating e Frumkin (2003) destacam em sua pesquisa que as contribuições às entidades sem fins lucrativos dependem da habilidade dessas organizações em comunicar seus resultados financeiros aos usuários. Diante disso, Trussel e Pearsons (2007) 
também destacaram em sua pesquisa que dentre os fatores que impactam as doações às empresas do terceiro setor está incluída a quantidade de informações fornecidas, além da reputação da entidade, sua eficiência e estabilidade financeira.

Brito et al. (2008), não diferentes dos demais pesquisadores, destacam que as informações provenientes dos demonstrativos contábeis das entidades sem fins lucrativos são úteis aos investidores, pois thes interessa saber a eficiência dos serviços prestados pelas entidades financiadas e a sua capacidade de continuar a prestá-los.

Diante disso, é fundamental às entidades do terceiro setor a divulgação de suas atividades desenvolvidas, incluindo suas arrecadações e gastos realizados na consecução de sua missão. Assim como as empresas evidenciam aos seus investidores e interessados seus resultados, as entidades sem fins lucrativos também devem evidenciar seus projetos desenvolvidos em consonância com seus objetivos à comunidade a qual serve (Cruz, 2010; Cunha \& Matias-Pereira, 2012).

Quanto à evidenciação do terceiro setor, que tem sido ponto de partida para estudos que relacionam doações e variáveis contábeis, Cruz (2010) e Piza et al. (2012) declaram que as demonstrações contábeis dessas entidades fornecem informações úteis que auxiliam os doadores em suas decisões de coação, e, de acordo com ludícibus (2010, p. 115) "a evidenciação é um compromisso inalienável da Contabilidade com seus usuários e com os próprios objetivos"; ainda que as formas de evidenciação variem, a essência é sempre a mesma.

Para Assis et al. (2006), a contabilidade tem um papel importante na solução das dificuldades que as entidades do terceiro setor enfrentam. Segundo os autores (2006), a contabilidade deve contribuir no processo de accountability, ou seja, fornecer informações necessárias aos investidores sociais para que possam verificar como estas entidades têm gerido os recursos que recebem.

$\mathrm{Na}$ visão de Carneiro et al. (2011), a utilização da contabilidade como ciência da informação para divulgação detalhada de informações à comunidade por meio das demonstrações contábeis e relatórios gerenciais contribui para a transparência da entidade, e é por meio dessa transparência que as organizações demonstram quem são e quais são seus objetivos.

Nessa perspectiva, é visível que a accountability é uma ferramenta fundamental para as entidades do terceiro setor e, por vezes, sua sobrevivência depende de sua transparência. Ademais, a divulgação deve ser completa e imparcial, apresentando a real situação da organização, sua eficiência e os projetos que tem desenvolvido junto à sociedade. Nesse processo, a contabilidade é fundamental e presta apoio fundamental às organizações sem fins lucrativos, uma vez que os investidores sociais utilizam as informações contábeis juntamente com as demais informações fornecidas pela entidade para decidirem quanto às suas doações.

\section{METODOLOGIA}

A fim de atender o objetivo proposto neste artigo, realizou-se uma pesquisa descritiva, conduzida por meio de análise documental e abordagem quantitativa. A população é composta por 76 entidades participantes do projeto "Desenvolvimento de Princípios de Transparência e Prestação de Contas em Organizações da Sociedade Civil", conduzido em parceria pelo Fundo Multilateral de Investimento (FUMIN) do Banco Interamericano de Desenvolvimento (BID) com a ONG Parceiros Voluntários (Menezes \& Johannpeter, 2012). O projeto foi desenvolvido com entidades do terceiro setor do estado do Rio Grande do Sul.

As entidades do terceiro setor analisadas nesta pesquisa participaram do projeto de capacitação de accountability da ONG Parceiros Voluntários com 0 Banco Interamericano de Desenvolvimento. Nesse projeto foram investidos US $\$ 800.000,00$ em 36 meses de execução. Teve inicio em 2006 com os primeiros estudos e a formalização da parceria; em 2008, teve início o projeto, com quatro pontos principais: a) o desenvolvimento dos princípios de transparência e prestação de contas; b) implementação das ações de transparência e prestação de contas; c) inclusão de princípios de transparência e prestação e contas para o fortalecimento do ambiente institucional; e d) disseminação dos resultados do projeto. (Menezes \& Johannpeter, 2012).

Como o objetivo desta pesquisa é identificar o nível de evidenciação contábil das entidades do terceiro setor participantes do projeto, foi excluída da amostra 1 (uma) entidade, por ser do primeiro setor, e selecionadas para amostra final 15 organizações que divulgaram a prestação de contas em seus sítios até o dia 10 de agosto de 2012. Como o projeto estimulou a divulgação das informações nos sítios das entidades, não se buscaram as demonstrações no sítio do Ministério da Justiça ou outros órgãos de controle. As organizações que compõem a amostra são apresentadas no Quadro 1.

Quadro 1 - Amostra da pesquisa

\begin{tabular}{|c|c|c|}
\hline & Entidades & $\begin{array}{c}\text { Cidade do } \\
\text { estado do } \\
\text { Rio Grande } \\
\text { do Sul }\end{array}$ \\
\hline 1 & $\begin{array}{l}\text { Associação Amparo à Maternidade e Infância } \\
\text { (ASSAMI) }\end{array}$ & Erechim \\
\hline 2 & Associação de Cegos Louis Braille (ACELB) & Porto Alegre \\
\hline 3 & Fundação Projeto Pescar (PROJETO PESCAR) & Porto Alegre \\
\hline 4 & $\begin{array}{l}\text { Centro de Equoterapia de Uruguaiana "Gen Fidélis" } \\
\text { (CEU) }\end{array}$ & Uruguaiana \\
\hline 5 & Viavida - Pró-doações e Transplantes & Porto Alegre \\
\hline 6 & $\begin{array}{l}\text { Associação Canoense de deficientes físicos } \\
\text { (ACADEF) }\end{array}$ & Canoas \\
\hline 7 & $\begin{array}{l}\text { Associação de Cegos do Rio Grande do Sul } \\
\text { (ACERGS) }\end{array}$ & Porto Alegre \\
\hline 8 & $\begin{array}{l}\text { Associação dos Moradores e Amigos da Vila Tronco } \\
\text { Neves e Arredores (AMAVTRON) }\end{array}$ & Porto Alegre \\
\hline 9 & Horta Comunitária Joana de Ângelis & $\begin{array}{l}\text { Novo } \\
\text { Hamburgo }\end{array}$ \\
\hline 10 & Instituto da Mama do Rio Grande do Sul & Porto Alegre \\
\hline 11 & $\begin{array}{l}\text { Instituto do Câncer Infantil do Rio Grande do Sul } \\
\text { (ICI) }\end{array}$ & Porto Alegre \\
\hline 12 & ONG Moradia e Cidadania & Porto Alegre \\
\hline 13 & Organização Beneficente Vida Viva & Porto Alegre \\
\hline 14 & ONG Parceiros Voluntários & Porto Alegre \\
\hline 15 & $\begin{array}{l}\text { União Brasileira de Educação e Assistência (UBEA } \\
\text { - PUCRS) }\end{array}$ & Porto Alegre \\
\hline
\end{tabular}


Para a coleta dos dados e para identificação do nível de evidenciação das entidades pesquisadas foi elaborado um construto com 53 itens de evidenciação contábil a partir do Pronunciamento Técnico CPC 26 que trata da apresentação das demonstrações contábeis. A escolha desse pronunciamento se deu em virtude de a estrutura das demonstrações contábeis ser a mesma para entidades do segundo e terceiro setor, exceto pela Demonstração de Superávit ou Déficit (Cruz, 2010), e devido o projeto estar embasado nos pronunciamentos técnicos emitidos pelo Comitê de Pronunciamentos Contábeis (CPC).

Em complemento ao construto elaborado a partir do CPC 26, foram incluídos 10 itens de evidenciação elaborados a partir da Norma Brasileira de Contabilidade NBC T 10.19, que trata especificamente das entidades do terceiro setor e indica itens de evidenciação que não estão contemplados no CPC.

Utilizaram-se as organizações que divulgaram a prestação de contas em seus sítios até o dia 10 de agosto de 2012, portanto, anterior a Resolução CFC no 1.409, de 21 de setembro de 2012, que aprovou a ITG 2002 - Entidade sem Finalidade de Lucros - e revogou a NBC T 10.19 - Entidades sem Finalidade de Lucros -; assim, a utilização da Norma Brasileira de Contabilidade NBC T 10.19 (revogada) em detrimento da ITG 2002 deve-se ao período de coleta de dados.

A utilização dessa norma se deu também em virtude de estar contemplada no projeto de igual modo aos CPCs. Esse construto foi elaborado na perspectiva da avaliação do nível de divulgação de informações contábeis vinculadas à prestação de contas inerente a este setor.

Os dados coletados foram tabulados e analisados atribuindo valor 1 (um) se a entidade apresenta a informação, 0 (zero) para o caso de não apresentar e nenhuma pontuação para situações em que a entidade não era obrigada a apresentar. $O$ índice de evidenciação das entidades do terceiro setor participantes do projeto foi obtido ao calcular a proporção de informações apresentadas em relação ao total de itens obrigatórios. Para apresentação dos resultados, utilizou-se a estatística descritiva por meio de tabelas.

Para analisar o nível de evidenciação das entidades, os itens foram divididos em três grupos. O primeiro grupo aborda a divulgação das Demonstrações Contábeis, o segundo grupo contempla a estrutura e conteúdo das Demonstrações Contábeis, e o terceiro grupo contém os itens exclusivos de evidenciação presentes na Norma Brasileira de Contabilidade da NBC T 10.19.

\section{APRESENTAÇÃO E ANÁLISE DOS RESULTADOS}

As entidades do terceiro setor analisadas participaram do projeto de capacitação de accountability da ONG Parceiros Voluntários com o Banco Interamericano de Desenvolvimento. Neste estudo, puderam-se analisar os resultados concretos e efetivos da prestação de contas das entidades. Das 76 entidades participantes, 15 disponibilizaram informações sobre transparência em seus sítios, ou seja, houve divulgação de apenas $20 \%$ das empresas participantes do projeto; entretanto, por meio de uma análise nos sítios das demais entidades, verificou-se que já existe a previsão de incluir área para prestação de contas.

Para analisar o nível de evidenciação das entidades, são apresentadas na Tabela 1 as Demonstrações Contábeis solicitadas pelas normas, bem como a quantidade de entidades que atenderam aos requisitos das normas relacionados à divulgação dessas demonstrações.

Tabela 1 - Demonstrações Contábeis - Apresentação apropriada e conformidade com as práticas contábeis

\begin{tabular}{|c|c|c|c|c|c|}
\hline \multirow[b]{3}{*}{ Item } & \multirow{3}{*}{$\begin{array}{c}\text { Check list - Pronunciamento Técnico CPC } 26 \text { e Norma Brasileira de } \\
\text { Contabilidade NBC T } 10.19\end{array}$} & \multicolumn{4}{|c|}{ Valores } \\
\hline & & \multicolumn{2}{|c|}{1} & \multicolumn{2}{|c|}{0} \\
\hline & & Obs. & $\%$ & Obs. & $\%$ \\
\hline 1 & Balanço Patrimonial ao final do período. & 7 & $47 \%$ & 8 & $53 \%$ \\
\hline 2 & Demonstração do Resultado do período. & 7 & $47 \%$ & 8 & $53 \%$ \\
\hline 3 & Demonstração do Resultado Abrangente do período. & 1 & $11 \%$ & 8 & $89 \%$ \\
\hline 4 & Demonstração das Mutações do Patrimônio Líquido (social) do período. & 4 & $27 \%$ & 11 & $73 \%$ \\
\hline 5 & Demonstração dos Fluxos de Caixa do período. & 3 & $20 \%$ & 12 & $80 \%$ \\
\hline 6 & $\begin{array}{l}\text { Notas explicativas, compreendendo um resumo das políticas contábeis significativas } \\
\text { e outras informações elucidativas. }\end{array}$ & 3 & $20 \%$ & 12 & $80 \%$ \\
\hline 7 & $\begin{array}{l}\text { Balanço Patrimonial do início do período mais antigo, comparativamente } \\
\text { apresentado, quando a entidade aplica uma política contábil retrospectivamente ou } \\
\text { procede à reapresentação retrospectiva de itens das demonstrações contábeis, ou } \\
\text { ainda quando procede à reclassificação de itens de suas demonstrações contábeis. }\end{array}$ & 0 & $0 \%$ & 15 & $100 \%$ \\
\hline 8 & Demonstração do valor adicionado do período. & 0 & $0 \%$ & 15 & $100 \%$ \\
\hline \multirow[t]{2}{*}{9} & $\begin{array}{l}\text { Declaração de forma explicita e sem reservas de que as demonstrações contábeis } \\
\text { da entidade estão ou não de acordo com os Pronunciamentos Técnicos, } \\
\text { Interpretações e Orientações do Comitê de Pronunciamentos Contábeis. }\end{array}$ & 3 & $20 \%$ & 12 & $80 \%$ \\
\hline & Evidenciação média & 3,1 & $21 \%$ & 11 & $79 \%$ \\
\hline
\end{tabular}

Quanto à apresentação apropriada e em conformidade com as práticas contábeis brasileiras, conforme a Tabela 1, 47\% das entidades apresentam Balanço Patrimonial e Demonstração de Resultado ao final do período, e $20 \%$ apresentam Demonstração de Fluxos de Caixa e notas explicativas. Nenhuma entidade apresenta Demonstração de Valor Adicionado, esta que poderia ser utilizada para apresentar os valores gerados pela entidade e expressar a aplicação dos recursos captados. 
Percebe-se que a maioria das entidades analisadas não divulgam as informações exigidas pelo CPC 26 e a NBC T 10.19, ou seja, quanto à divulgação das demonstrações contábeis, o nível médio de evidenciação das entidades pesquisadas é de $21 \%$; esse nível pode ser considerado baixo e contrapõe o exposto pela teoria (Goulart, 2003; Almeida \& Ferreira, 2007; Costa et al., 2011), podendo ser um fator limitador de doações recebidas por essas entidades (Keating \& Frumkin, 2003; Cruz, 2010).

Tabela 2 - Demonstrações Contábeis - Materialidade e agregação e compensação de valores

\begin{tabular}{|c|c|c|c|c|c|}
\hline \multirow[b]{3}{*}{ Item } & \multirow{3}{*}{$\begin{array}{l}\text { Check list - Pronunciamento Técnico CPC } 26 \text { e Norma Brasileira de Contabilidade } \\
\text { NBC T } 10.19\end{array}$} & \multicolumn{4}{|c|}{ Valores } \\
\hline & & \multicolumn{2}{|c|}{1} & \multicolumn{2}{|c|}{0} \\
\hline & & Obs. & $\%$ & Obs. & $\%$ \\
\hline 10 & Classes materiais de itens semelhantes apresentadas separadamente. & 7 & $47 \%$ & 8 & $53 \%$ \\
\hline 11 & Itens materiais e de natureza ou função distintas apresentados separadamente. & 8 & $53 \%$ & 7 & $47 \%$ \\
\hline 12 & Ativos e passivos informados separadamente. & 7 & $47 \%$ & 8 & $53 \%$ \\
\hline \multirow[t]{2}{*}{13} & Receitas e despesas informadas separadamente. & 8 & $53 \%$ & 7 & $47 \%$ \\
\hline & Evidenciação média & 7,5 & $50 \%$ & 7,5 & $50 \%$ \\
\hline
\end{tabular}

Quanto à materialidade e compensação de valores (Tabela 2), $47 \%$ das entidades separam os itens em classes materiais e apresentam ativos e passivos separadamente, e $53 \%$ das entidades informam separadamente receitas e despesas em itens materiais de natureza e função distinta, podendo assim entender a destinação dos recursos.

Tabela 3 - Demonstrações Contábeis - Informação Comparativa

\begin{tabular}{|c|c|c|c|c|c|}
\hline \multirow[b]{3}{*}{ Item } & \multirow{3}{*}{$\begin{array}{c}\text { Check list - Pronunciamento Técnico CPC } 26 \text { e Norma Brasileira de } \\
\text { Contabilidade NBC T } 10.19\end{array}$} & \multicolumn{4}{|c|}{ Valores } \\
\hline & & \multicolumn{2}{|c|}{1} & \multicolumn{2}{|c|}{0} \\
\hline & & Obs. & $\%$ & Obs. & $\%$ \\
\hline 14 & $\begin{array}{l}\text { Apresentação de, no mínimo, dois balanços patrimoniais com as informações } \\
\text { comparativas com respeito ao período anterior para todos os montantes apresentados } \\
\text { na demonstração contábil do período corrente }\end{array}$ & 6 & $40 \%$ & 9 & $60 \%$ \\
\hline 15 & $\begin{array}{l}\text { Apresentação de, no mínimo, duas demonstrações do resultado com as informações } \\
\text { comparativas com respeito ao período anterior para todos os montantes apresentados } \\
\text { na demonstração contábil do período corrente }\end{array}$ & 6 & $40 \%$ & 9 & $60 \%$ \\
\hline 16 & $\begin{array}{l}\text { Apresentação de, no mínimo, duas demonstrações do resultado abrangente com as } \\
\text { informações comparativas com respeito ao período anterior para todos os montantes } \\
\text { apresentados na demonstração contábil do período corrente }\end{array}$ & 1 & $11 \%$ & 8 & $89 \%$ \\
\hline 17 & $\begin{array}{l}\text { Apresentação de, no mínimo, duas demonstrações das mutações do patrimônio } \\
\text { líquido com as informações comparativas com respeito ao período anterior para todos } \\
\text { os montantes apresentados na demonstração contábil do período corrente }\end{array}$ & 3 & $20 \%$ & 12 & $80 \%$ \\
\hline 18 & $\begin{array}{l}\text { Apresentação de, no mínimo, duas demonstrações dos fluxos de caixa com as } \\
\text { informações comparativas com respeito ao período anterior para todos os montantes } \\
\text { apresentados na demonstração contábil do período corrente }\end{array}$ & 3 & $20 \%$ & 12 & $80 \%$ \\
\hline \multirow[t]{2}{*}{19} & $\begin{array}{l}\text { Apresentação de, no mínimo, duas demonstrações do valor adicionado com as } \\
\text { informações comparativas com respeito ao período anterior para todos os montantes } \\
\text { apresentados na demonstração contábil do período corrente }\end{array}$ & 0 & $0 \%$ & 15 & $100 \%$ \\
\hline & Evidenciação média & 3,2 & $22 \%$ & 11 & $78 \%$ \\
\hline
\end{tabular}

Conforme a Tabela 3, das entidades que apresentaram demonstrações contábeis, $40 \%$ delas apresentam de forma comparativa o Balanço Patrimonial e Demonstração de Resultado e apenas uma apresentou Demonstração do Resultado Abrangente. A Demonstração de Mutações do Patrimônio e a Demonstração dos Fluxos de Caixa foram apresentadas comparativamente por $20 \%$ das entidades. De igual modo ao apresentado na Tabela 1, quanto à comparabilidade das demonstrações, vê-se que o nível de evidenciação das empresas analisadas é baixo.
Nas tabelas seguintes apresenta-se como está estruturado e a qualidade do conteúdo das evidenciações contábeis na prestação de contas das entidades. A Tabela 4 apresenta a identificação das demonstrações, na qual $60 \%$ das entidades não têm a preocupação de distinguir as demonstrações contábeis dos demais relatórios de prestação de contas. Os relatórios evidenciam claramente o nome da entidade para $67 \%$ da amostra, mas nenhuma menciona se as demonstrações pertencem a um grupo ou são informações individuais. 
Tabela 4 - Estrutura e Conteúdo - Identificação das demonstrações contábeis

\begin{tabular}{|c|c|c|c|c|c|}
\hline \multirow[b]{3}{*}{ Item } & \multirow{3}{*}{$\begin{array}{l}\text { Check list - Pronunciamento Técnico CPC } 26 \text { e Norma Brasileira de Contabilidade } \\
\text { NBC T } 10.19\end{array}$} & \multicolumn{4}{|c|}{ Valores } \\
\hline & & \multicolumn{2}{|c|}{1} & \multicolumn{2}{|c|}{0} \\
\hline & & Obs. & $\%$ & Obs. & $\%$ \\
\hline 20 & $\begin{array}{l}\text { Demonstrações contábeis identificadas claramente e distinguidas de qualquer outra } \\
\text { informação que porventura conste no mesmo documento }\end{array}$ & 6 & $40 \%$ & 9 & $60 \%$ \\
\hline 21 & $\begin{array}{l}\text { Nome da entidade às quais as demonstrações contábeis dizem respeito ou outro meio } \\
\text { que permita sua identificação, bem como qualquer alteração que possa ter ocorrido } \\
\text { nessa identificação desde o término do período anterior }\end{array}$ & 10 & $67 \%$ & 5 & $33 \%$ \\
\hline 22 & $\begin{array}{l}\text { Se as demonstrações contábeis se referem a uma entidade individual ou a um grupo de } \\
\text { entidades }\end{array}$ & 0 & $0 \%$ & 15 & $100 \%$ \\
\hline 23 & $\begin{array}{l}\text { Data de encerramento do período de reporte ou o período coberto pelo conjunto de } \\
\text { demonstrações contábeis ou notas explicativas }\end{array}$ & 7 & $47 \%$ & 8 & $53 \%$ \\
\hline 24 & Moeda de apresentação & 5 & $33 \%$ & 10 & $67 \%$ \\
\hline \multirow[t]{2}{*}{25} & $\begin{array}{l}\text { Nível de arredondamento usado na apresentação dos valores nas demonstrações } \\
\text { contábeis }\end{array}$ & 8 & $53 \%$ & 7 & $47 \%$ \\
\hline & Evidenciação média & 6 & $40 \%$ & 9 & $60 \%$ \\
\hline
\end{tabular}

A Tabela 5 apresenta a estrutura e conteúdo das demonstrações contábeis. As informações com maior nível de evidenciação são a subclassificação das despesas, com índice de $53 \%$; segregação das contas do ativo e passivo circulante, ativos circulantes e não circulantes e passivos circulantes e não circulantes apresentados separadamente; segregação das contas da Demonstração do Resultado e a inexistência de rubrica ou itens de receitas ou despesas como itens extraordinários com índice de evidenciação igual a $47 \%$.

Apenas $27 \%$ das entidades detalham as subdivisões do ativo, e apenas duas entidades apresentam e descrevem as reservas constituídas no Patrimônio Líquido. Na Demonstração de Resultado, existe para $53 \%$ das entidades a preocupação em detalhar sinteticamente as despesas, mas não há preocupação em apresentar a função, a natureza ou informações adicionais.

Tabela 5 - Estrutura e Conteúdo - demonstrações contábeis

\begin{tabular}{|c|c|c|c|c|c|}
\hline \multirow[b]{3}{*}{ Item } & \multirow{3}{*}{$\begin{array}{c}\text { Check list - Pronunciamento Técnico CPC } 26 \text { e Norma Brasileira de } \\
\text { Contabilidade NBC T } 10.19\end{array}$} & \multicolumn{4}{|c|}{ Valores } \\
\hline & & \multicolumn{2}{|c|}{1} & \multicolumn{2}{|c|}{0} \\
\hline & & Obs. & $\%$ & Obs. & $\%$ \\
\hline 26 & Segregação das contas do ativo e passivo circulante. & 7 & $47 \%$ & 8 & $53 \%$ \\
\hline 27 & $\begin{array}{l}\text { Ativos circulantes e não circulantes e passivos circulantes e não circulantes } \\
\text { apresentados separadamente. }\end{array}$ & 7 & $47 \%$ & 8 & $53 \%$ \\
\hline 28 & $\begin{array}{l}\text { Subdivisão do ativo não circulante em realizável a longo prazo, investimentos, } \\
\text { imobilizado e intangível. }\end{array}$ & 4 & $27 \%$ & 11 & $73 \%$ \\
\hline 29 & $\begin{array}{l}\text { Descrição da natureza e da finalidade de cada reserva dentro do patrimônio } \\
\text { líquido. }\end{array}$ & 2 & $18 \%$ & 9 & $82 \%$ \\
\hline 30 & Segregação das contas da Demonstração do Resultado. & 7 & $47 \%$ & 8 & $53 \%$ \\
\hline 31 & Na Demonstração do Resultado, o resultado líquido do período. & 6 & $40 \%$ & 9 & $60 \%$ \\
\hline 32 & Na Demonstração do Resultado Abrangente, o resultado líquido do período. & 1 & $11 \%$ & 8 & $89 \%$ \\
\hline 33 & $\begin{array}{l}\text { Na Demonstração do Resultado Abrangente, cada item dos outros resultados } \\
\text { abrangentes classificados conforme sua natureza. }\end{array}$ & 1 & $11 \%$ & 8 & $89 \%$ \\
\hline 34 & Na Demonstração do Resultado Abrangente, o resultado abrangente do período. & 1 & $11 \%$ & 8 & $89 \%$ \\
\hline 35 & $\begin{array}{l}\text { Inexistência de rubrica ou itens de receitas ou despesas como itens } \\
\text { extraordinários. }\end{array}$ & 7 & $47 \%$ & 8 & $53 \%$ \\
\hline 36 & $\begin{array}{l}\text { Montante do efeito tributário relativo a cada componente dos outros resultados } \\
\text { abrangentes, incluindo os ajustes de reclassificação. }\end{array}$ & 0 & $0 \%$ & 8 & $100 \%$ \\
\hline 37 & $\begin{array}{l}\text { Ajustes de reclassificação relativos a componentes dos outros resultados } \\
\text { abrangentes. }\end{array}$ & 0 & $0 \%$ & 8 & $100 \%$ \\
\hline 38 & Subclassificação das despesas. & 8 & $53 \%$ & 7 & $47 \%$ \\
\hline 39 & $\begin{array}{l}\text { Em apresentando os gastos por função, informações adicionais sobre a natureza } \\
\text { das despesas, incluindo despesas de depreciação e de amortização e as } \\
\text { despesas com benefícios a empregados. }\end{array}$ & 0 & $0 \%$ & 9 & $100 \%$ \\
\hline 40 & Conciliação do saldo no início e no final do período. & 4 & $27 \%$ & 11 & $73 \%$ \\
\hline 41 & $\begin{array}{l}\text { Para cada componente do patrimônio líquido, uma análise, por meio da } \\
\text { Demonstração das Mutações do Patrimônio Líquido ou das notas explicativas, dos } \\
\text { outros resultados abrangentes por item. }\end{array}$ & 1 & $9 \%$ & 10 & $91 \%$ \\
\hline 42 & Segregação das contas do patrimônio líquido. & 4 & $27 \%$ & 11 & $73 \%$ \\
\hline & Evidenciação média & 3,5 & $25 \%$ & 8,8 & $75 \%$ \\
\hline
\end{tabular}


Os dados expostos na Tabela 5 não diferem, em média, dos apresentados nas Tabelas 1 e 3 , em que é perceptível um baixo nível de evidenciação contábil por parte das entidades do terceiro setor que compuseram a amostra desta pesquisa.

Em relação às notas explicativas, como demonstrado na Tabela $6,80 \%$ das entidades apresentam qualitativamente os objetivos, políticas e gestão do capital e $87 \%$ discriminam suas principais atividades e operações, $67 \%$ sintetizam as informações quantitativas da gestão do capital, e 53\% apresentam as comprovações de registro e legalidade da entidade, demonstrando assim o enfoque qualitativo na prestação de contas, sendo que os demais itens das notas explicativas são apresentados por menos de $20 \%$ das entidades.

Tabela 6 - Estrutura e Conteúdo - notas explicativas

\begin{tabular}{|c|c|c|c|c|c|}
\hline \multirow[b]{3}{*}{ Item } & \multirow{3}{*}{$\begin{array}{l}\text { Check list - Pronunciamento Técnico CPC } 26 \text { e Norma Brasileira de Contabilidade } \\
\text { NBC T } 10.19\end{array}$} & \multicolumn{4}{|c|}{ Valores } \\
\hline & & \multicolumn{2}{|c|}{1} & \multicolumn{2}{|c|}{$\mathbf{0}$} \\
\hline & & Obs. & $\%$ & Obs. & $\%$ \\
\hline 43 & $\begin{array}{l}\text { Base para a elaboração das demonstrações contábeis e das políticas contábeis } \\
\text { específicas utilizadas }\end{array}$ & 3 & $20 \%$ & 12 & $80 \%$ \\
\hline 44 & Referência cruzada entre os itens das demonstrações contábeis e as notas explicativas & 2 & $13 \%$ & 13 & $87 \%$ \\
\hline 45 & $\begin{array}{l}\text { Base (ou bases) de mensuração utilizada(s) na elaboração das demonstrações } \\
\text { contábeis, apresentadas no resumo de políticas contábeis significativas }\end{array}$ & 3 & $20 \%$ & 12 & $80 \%$ \\
\hline 46 & $\begin{array}{l}\text { Outras políticas contábeis utilizadas relevantes, apresentadas no resumo de políticas } \\
\text { contábeis significativas }\end{array}$ & 3 & $20 \%$ & 12 & $80 \%$ \\
\hline 47 & $\begin{array}{l}\text { Os julgamentos realizados que a administração fez no processo de aplicação das } \\
\text { políticas contábeis da entidade, com exceção dos que envolvem estimativas }\end{array}$ & 2 & $14 \%$ & 12 & $86 \%$ \\
\hline 48 & $\begin{array}{l}\text { Informação acerca dos pressupostos relativos ao futuro e outras fontes principais de } \\
\text { incerteza nas estimativas que possuam risco significativo de provocar ajuste material } \\
\text { nos valores contábeis, incluindo a natureza do ativo e/ou passivo e o seu valor contábil }\end{array}$ & 1 & $7 \%$ & 14 & $93 \%$ \\
\hline 49 & $\begin{array}{l}\text { Informações qualitativas sobre os seus objetivos, políticas e processos de gestão do } \\
\text { capital }\end{array}$ & 12 & $80 \%$ & 3 & $20 \%$ \\
\hline 50 & Dados quantitativos sintéticos sobre os elementos incluídos na gestão do capital. & 10 & $67 \%$ & 5 & $33 \%$ \\
\hline 51 & $\begin{array}{l}\text { Indicação do cumprimento ou não, durante o período, dos eventuais requisitos de capital } \\
\text { impostos externamente }\end{array}$ & 1 & $7 \%$ & 14 & $93 \%$ \\
\hline 52 & $\begin{array}{l}\text { Domicílio e a forma jurídica da entidade, o seu país de registro e o endereço da sede } \\
\text { registrada }\end{array}$ & 8 & $53 \%$ & 7 & $47 \%$ \\
\hline \multirow[t]{2}{*}{53} & Descrição da natureza das operações da entidade e das suas principais atividades & 13 & $87 \%$ & 2 & $13 \%$ \\
\hline & Evidenciação média & 5,3 & $35 \%$ & 9,6 & $65 \%$ \\
\hline
\end{tabular}

A NBC T 10.19, além de estabelecer elementos comuns ao CPC 26, também apresenta informações exclusivas de entidades do terceiro setor, entre elas informações de subvenções, doações e aplicação de recursos. Os itens de divulgação adicionais ao CPC
26 apresentados pelas NBC T 10.19 são apresentados na Tabela 7, juntamente com os índices de evidenciação das entidades analisadas.

Tabela 7 - Evidenciação dos itens exclusivos da Norma Brasileira de Contabilidade NBC T 10.19

\begin{tabular}{|c|c|c|c|c|c|}
\hline \multirow[b]{3}{*}{ Item } & \multirow{3}{*}{$\begin{array}{c}\text { Check list - Pronunciamento Técnico CPC } 26 \text { e Norma Brasileira de } \\
\text { Contabilidade NBC T } 10.19\end{array}$} & \multicolumn{4}{|c|}{ Valores } \\
\hline & & \multicolumn{2}{|c|}{1} & \multicolumn{2}{|c|}{0} \\
\hline & & Obs. & $\%$ & Obs. & $\%$ \\
\hline 54 & $\begin{array}{l}\text { Contribuições previdenciárias relacionadas com a atividade assistencial como se a } \\
\text { entidade não gozasse de isenção. }\end{array}$ & 2 & $13 \%$ & 13 & $87 \%$ \\
\hline 55 & $\begin{array}{l}\text { Subvenções recebidas, a aplicação dos recursos e as responsabilidades } \\
\text { decorrentes dessas subvenções. }\end{array}$ & 4 & $33 \%$ & 8 & $67 \%$ \\
\hline 56 & Os fundos de aplicação restrita e responsabilidades decorrentes desses fundos & 1 & $10 \%$ & 9 & $90 \%$ \\
\hline 57 & Recursos sujeitos a restrições ou vinculações por parte do doador & 1 & $10 \%$ & 9 & $90 \%$ \\
\hline 58 & $\begin{array}{l}\text { Eventos subsequentes à data do encerramento do exercício que tenham, ou } \\
\text { possam vir a ter efeito relevante sobre a situação financeira e os resultados futuros } \\
\text { da entidade }\end{array}$ & 1 & $7 \%$ & 14 & $93 \%$ \\
\hline 59 & Taxas de juros das obrigações a longo prazo. & 0 & $0 \%$ & 8 & $100 \%$ \\
\hline 60 & Datas de vencimento das obrigações a longo prazo. & 0 & $0 \%$ & 8 & $100 \%$ \\
\hline 61 & Garantias das obrigações a longo prazo. & 0 & $0 \%$ & 8 & $100 \%$ \\
\hline 62 & Informações sobre os tipos de seguro contratados. & 3 & $20 \%$ & 12 & $80 \%$ \\
\hline \multirow[t]{2}{*}{63} & $\begin{array}{l}\text { As receitas com e sem gratuidade de forma segregada, e os benefícios fiscais } \\
\text { gozados, para as entidades beneficiadas com isenção de tributos e contribuições. }\end{array}$ & 1 & $8 \%$ & 11 & $92 \%$ \\
\hline & Evidenciação média & 1,3 & $10 \%$ & 10 & $90 \%$ \\
\hline
\end{tabular}


Conforme a Tabela 7, comparativamente aos demais itens, apresenta os menores níveis, $13 \%$ das entidades divulgaram informações relacionadas a informações previdenciárias da atividade assistencial, 33\% divulgaram informações de subvenções recebidas e suas aplicações e responsabilidades, $20 \%$ das entidades apresentaram os seguros contratatos, e apenas uma entidade apresenta informações sobre doações recebidas e isenções fiscais.
Analisando os três blocos de evidenciações, os resultados demonstram uma preocupação com as informações qualitativas na prestação de contas, com baixo nível de evidenciação das informações contábeis e apresentação sintética das informações quantitativas, resumidas no Balanço Patrimonial e Demonstração do Resultado. Os níveis médios de evidenciação por bloco de análise e a média geral de evidenciação são apresentadas na Tabela 8.

Tabela 8 - Estatística descritiva do nível de evidenciação.

\begin{tabular}{|c|c|c|c|}
\hline Blocos de análise & Média & Máximo & Mínimo \\
\hline 1ํBloco - Demonstrações contábeis & $27,49 \%$ & $53,33 \%$ & $0,00 \%$ \\
\hline $2^{\circ}$ Bloco - Estrutura e conteúdo & $30,83 \%$ & $86,67 \%$ & $0,00 \%$ \\
\hline 3ํㅗ Bloco - Itens exclusivos da NBC T 10.19 & $10,17 \%$ & $33,33 \%$ & $0,00 \%$ \\
\hline Índice geral & $26,54 \%$ & $86,67 \%$ & $0,00 \%$ \\
\hline
\end{tabular}

Percebe-se, por meio da análise da Tabela 8, que a média de evidenciação das entidades do terceiro setor que compuseram a amostra desta pesquisa é baixa em todos os blocos analisados. Em todos os blocos de análise, verifica-se que houve itens que não foram divulgados por nenhuma das entidades pesquisadas, e, de igual modo, nenhum item foi evidenciado pela totalidade da amostra.

Em uma análise por organização, identificou-se que a entidade com maior atendimento às normas apresentou um índice de evidenciação de 84,91\%; em contraponto, há uma entidade que evidenciou apenas $3,17 \%$ dos itens exigidos pelas normas. Esses dados apontam para um baixo atendimento às normas por essas entidades, ainda que haja o fomento da prestação de contas por meio do projeto "Desenvolvimento de Princípios de Transparência e Prestação de Contas em Organizações da Sociedade Civil”. As três entidades que apresentaram índice superior a $80 \%$ de evidenciação possuem estrutura administrativa nos moldes de grandes organizações empresariais privadas (conselho de administração, diretoria executiva), submetendo à auditoria externa suas demonstrações financeiras. Nas entidades com menor índice de evidenciação, a prestação de contas é desenvolvida por voluntários, sem uma estrutura administrativa fixa para auxílio à prestação de contas.

Como visto na teoria, as entidades do terceiro setor possuem uma obrigação de prestação de contas subjacente à gestão dos recursos obtidos junto à sociedade por meio das doações recebidas (Almeida \& Ferreira, 2007; Costa et al., 2011; Oliveira \& Torres, 2011). A desconfiança da sociedade perante essas entidades é gerada pela sua falta de transparência (Falconer, 1999).

A relevância da prestação de contas é vista ainda quando da sua relação com o nível de doações recebidas pelas entidades do terceiro setor (Weisbrod \& Dominguez, 1986; Keating \& Frumkin, 2003; Brito et al., 2008). Apesar de tais evidências, esta pesquisa corrobora com os achados de Cruz (2010) e Carneiro et al. (2011) de que as entidades do terceiro setor não possuem como prática a prestação de contas e, conforme salientado pelos autores, essa ausência de transparência pode limitar as doações recebidas por essas entidades, ou seja, impedir que possam contribuir de forma mais atuante na sociedade.

\section{CONCLUSÃO}

Este artigo objetivou identificar o nível de evidenciação contábil das entidades do terceiro setor participantes do projeto, em parceria da ONG Parceiros Voluntários com o Banco Interamericano de Desenvolvimento (BID/FUMIN), "Desenvolvimento de Princípios de Transparência e Prestação de Contas em Organizações da Sociedade Civil". Foram coletadas as informações para estudo no sítio das entidades participantes, analisando todos os relatórios relacionados com a prestação de contas e transparência e comparados com o CPC 26 e NBC T 10.19 para dimensionar o comprimento das exigências.

Do projeto que serviu de base para o presente estudo, participaram 75 entidades do terceiro setor, e, depois de 3 etapas, contemplando planejamento, estudos e acompanhamentos, apenas 15 entidades apresentam como proposto as informações referente à transparência e à prestação de contas. $\mathrm{O}$ estudo não teve por objetivo verificar o cumprimento de obrigações legais perante órgãos fiscalizadores, e sim verificar a transparência com usuários gerais, que buscam nos sítios das entidades informações sobre os recursos capitados e aplicados.

Após análise dos 63 itens de evidenciação, divididos em 3 grupos, constatou-se que, no que se refere aos requisitos das Demonstrações Contábeis de acordo com o CPC 26, o índice de evidenciação médio das entidades foi de $27 \%$, ou seja, as entidades atenderam parcialmente à norma. No que se refere à estrutura e conteúdo das prestações de contas analisadas, identificou-se um índice de evidenciação médio de 31\%; percebeuse aí um aumento no atendimento a norma, pois nesse item apresentam-se as informações qualitativas e quantitativas sintetizadas, o que demonstra, portanto, a preocupação em contar como e o que a entidade realiza e não apresentar monetariamente esses fatos. Quanto às exigências complementares da NBC T 10.19, constatou-se o menor nível de atendimento, com índice médio de evidenciação de apenas 10\%. 
Conclui-se que o nível médio de evidenciação das entidades participantes do projeto foi de $27 \%$, um índice considerado baixo, que pode denotar a não percepção por essas entidades da importância da prestação de contas e transparência desse setor como visto apontado na literatura.

Destaca-se que os resultados desta pesquisa não podem ser generalizados em virtude do número reduzido da amostra. Recomenda-de, portanto, para pesquisas futuras, a ampliação da amostra e a pesquisa junto às entidades a fim de identificar quais os meios utilizados por elas para prestação de contas junto à comunidade.

\section{REFERÊNCIAS}

Almeida, M. C. \& Ferreira, E. S. (2007). Terceiro setor: prestação de contas e suas implicações. Horizonte científico. 1(1), 1-22.

Araujo, O. C. (2005). Contabilidade para organizações do Terceiro setor. São Paulo: Atlas.

Assis, M. S., Mello, G. R. \& Slomski, V. (2006). Transparência nas entidades do Terceiro Setor. A demonstração do resultado econômico como instrumento de mensuração do desempenho. In: Congresso USP de Iniciação Científica em Contabilidade, III, São Paulo, 2006. Anais... São Paulo, FEA/USP.

Atan, R., Zainon, S. \& Wah, Y. B. (2012). Quality information by charity organizations and its relationship with donations. In: Conference on Business administration, 2012. Cambridge. Proceedings... 6으 WSEAS Conferência internacional em administração de negócios, Harvard.

Brito, P. P., Oliveira, M. C., Santos, S. M. dos, Luca, M. M. M. de \& Oliveira, B. C. de. (2008). A utilização dos demonstrativos contábeis como instrumento de apoio a gestão nas organizações não governamentais: um estudo de caso no estado do Ceará. Revista alcance, 15(1), 61-80.

Campos, G. M., Moreira, R. de L. \& Scalzer, R. S. (2014). Financial reporting: reflection on transparency in the third sector. Sociedade, contabilidade e gestão, 9(3), 130-142.

Carneiro, A. de F., Oliveira, D. de L. \& Torres, L. C. (2011). Accountability e a prestação de contas das organizações do terceiro setor: uma abordagem à relevância da contabilidade. Sociedade, contabilidade e gestão, 6(2), 90105.

Coelho, S. de C. C. (2000). Terceiro Setor: um estudo comparado entre Brasil e Estados Unidos. São Paulo: SENAC.

Costa, E., Ramus, T. \& Andreaus, M. (2011). Accountability as a managerial tool in non-profit organizations: evidence from Italian CSVs. Voluntas, 22(3), 470-493.

Cunha J. H. da C. \& Matias-Pereira, J. (2012). Captação de recursos no terceiro setor: fatores estratégicos para divulgação de informações. Revista Contemporânea de Contabilidade, v. 9(18), 83-102.
Cruz, C. V. O. A. (2010). A relevância da informação contábil para os investidores sociais privados de entidades do terceiro setor no Brasil: Uma investigação empírica. Tese de doutorado em Contabilidade, Universidade de São Paulo, São Paulo, SP, Brasil.

Cruz, J. A. W., Quandt, C. O., Martins, T. S. \& Silva, W. V. da. (2010) Performance no terceiro setor - uma abordagem de accountability: estudo de caso em uma organização não governamental brasileira. Revista de administração da UFSM, 3(1), 58-75.

Ebsen, K. \& Laffin, M. (2004). Terceiro Setor e Contabilidade: compilações de uma pesquisa. Revista Contemporânea de Contabilidade, 1(1) 11-28.

Falconer, A. P. (1999). A promessa do Terceiro Setor: um estudo sobre a construção do papel das organizações sem fins lucrativos e do seu campo de gestão. Dissertação de mestrado,Universidade de São Paulo, São Paulo, $\mathrm{SP}$, Brasil.

Gandía, J. L. (2011). Internet disclosure by nonprofit organizations: empirical evidence of nongovernmental organizations for development in Spain. Nonprofit and voluntary sector quarterly, 40(1), 57-78.

Goulart, A. M. C. (2003). Evidenciação contábil do risco de mercado por instituições financeiras no brasil. Dissertação de mestrado, Universidade de São Paulo. São Paulo, SP, Brasil.

ludícibus, S. (2010). Teoria da contabilidade. (10 ed.) São Paulo: Atlas.

Keating, E. K. \& Frumkin, P. (2003). Reengineering nonprofit financial accountability: toward a more reliable foundation for regulation. Public Administration Review, 63(1), 3-15

Lei no 13.019, de 31 de julho de 2014 (2014). Recuperado em 27 julho, 2014, de http://www.planalto.gov.br/ccivil_03/_Ato20112014/2014/Lei/L13019.htm.

Menezes, N. \& Johannpeter, M. E. P. (2012). ONG transparência como fator crítico de sucesso. Porto Alegre: Ed. Unisinos.

Olak, P. A. \& Nascimento, D. T. (2010). Contabilidade para Entidades sem Fins Lucrativos (Terceiro Setor). (3 ed.) São Paulo: Atlas.

Oliveira, I. M. da S. (2009). Uma investigação sobre a prestação de contas das entidades do terceiro setor brasileiro. Dissertação de mestrado, Universidade Federal de Pernambuco, Recife, Brasil.

Piza, S. C. de T., Parisi, C., Megliorini, E. \& Gallo, M. F. (2012). A aderência das práticas contábeis das entidades do terceiro setor às normas brasileiras de contabilidade: um estudo multicaso de entidades do município de São Paulo-SP. Revista de Contabilidade do Mestrado em Ciências Contábeis da UERJ, 17(3), 78-97.

Soldi, A. R., Hatz, C. R., Santos, G. R. dos \& Silva, M. M. da. (2007). Transparência no terceiro setor: um estudo sobre as organizações filantrópicas. Jovens Pesquisadores, 4(1), 1-13.

Trussel, J. M. \& Parsons, L. M. (2007). Financial reporting factors affecting donations to charitable organizations. Advances in Accounting, 23, 263-285. Weisbrod, B. A. \& Dominguez, N. D. (1986). Demand for collective goods in private nonprofit markets: can fundraising expenditures help overcome freerider behavior? Journal of public economics, 30(1), 83-96.

Zainon, S., Atan, R., Wah, Y. B. \& Ahmad, R. A. R. (2012). Information disclosure by charity organizations. In: Conference on Business administration, 2012. Cambridge. Proceedings... 6으 WSEAS Conferência internacional em administração de negócios, Harvard. 